\title{
Advanced Materials World Congress (AMWC)
}

\section{Dear Readers,}

We are glad to announce Advanced Materials Word Congress (AMWC, http://www.amwc2013.org/) together with the International Association of Advanced Materials (www.iaamonline.org) and hosted by the İzmir Institute of Technology in the beautiful coastal town Çeşme, Turkey at Altinyunus Hotel Cessme during 16-19 September, 2013. The goal of congress is to provide a global platform for researchers and engineers coming from academia and industry to present their research results and activities in the field of materials science and engineering with a special attention on interdisciplinary research of advanced materials. The conference will provide opportunities for the delegates to exchange their face-to-face novel ideas and experiences with the international experts during plenary \& invited talks, oral presentations and poster sessions. We will set up ten sessions with keynote forum, panel discussion and project negotiation. The full article of presentations will be published in the special issue of Advanced Materials Letters.

Advanced Materials Word Congress will be focused on 10 topics including all the forefront of the field. The dedicated sessions will be organized in the following topics:

Session 1: Biomaterials

Session 2: Energy materials

Session 3: Optical and electronic materials

Session 4: Magnetic materials

Session 5: Structural materials

Session 6: Polymers

Session 7: Composite materials

Session 8: Constructional materials

Session 9: Nano materials

Session 10: Environmental and green materials

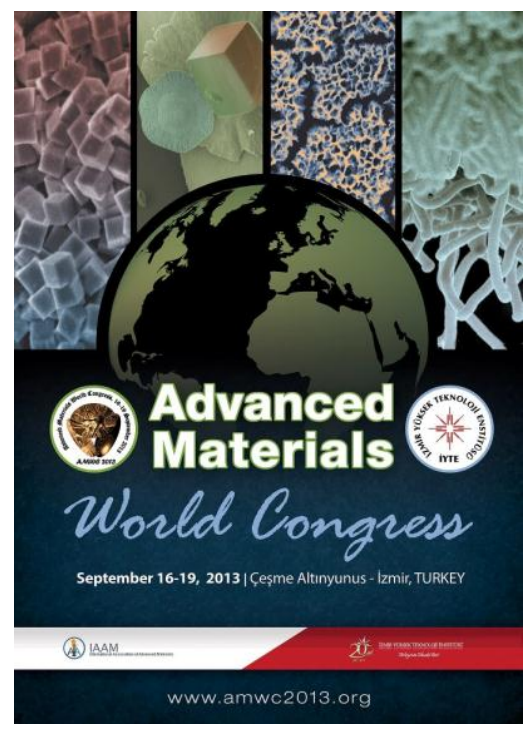

Banner of Advanced Materials World Congress.
In the world congress, Prof. Ashutosh Tiwari, Editorin-Chief, Advanced Materials Letters will honor outstanding authors with AML award for their notable and outstanding research contribution to the Advanced Materials Letters in 2012 and 2013.

We trust that Advanced Materials Letters provides an global platform \& sources to the researchers, teachers and students active in the fields of applied or fundamental materials science related to biological, chemical, earth, atmosphere, ocean and planetary, engineering, mathematical, medical and physical sciences. The journal is expected to become popular accompanied with a high impact factor in June 2013 and hopefully we, as editors, may welcome you as readers, authors or reviewers in near future. Your opinions and suggestions are greatly valued for the development of this journal.

With kindest regards

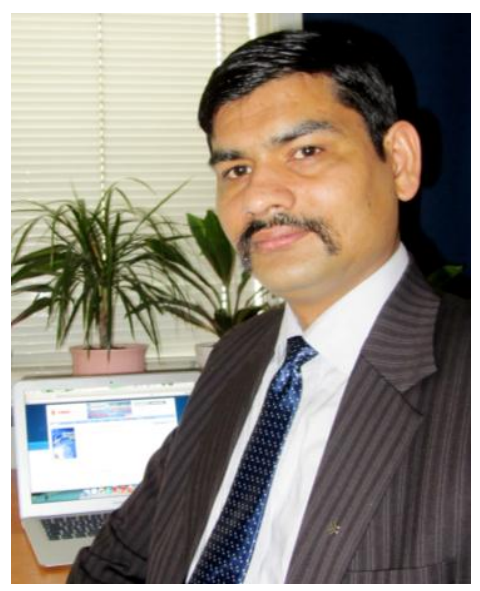

Ashutosh Tiwari, PhD

Editor-in-Chief

Biosensors \& Bioelectronics Centre IFM-Linköping University, Sweden 